\title{
Climate change wars stall government plan
}

The Kyoto Protocol to combat climate change enters into force Feb. 16, leaving Canada with the mammoth challenge of cutting its greenhouse gas emissions by $20 \%-25 \%$ over the next 5 years.

Canada has committed to reducing greenhouse gas emissions to $6 \%$ below 1990 levels by 2010 - a reduction of 300 megatonnes per year, according to the Vancouver-based Sage Climate Project. At press time, the federal Climate Change Secretariat did not yet have a plan that accounts for that entire reduction.

Infighting among federal government departments - Natural Resources Canada and Environment Canada, with some weighin by Industry Canada - has meant that there is no clear lead agency and no single vision of how to achieve Canada's commitments.

"There's open warfare within the government about what it should be doing," said one source following the file.

An intense industry lobby, led by Alberta and the Canadian
Council of Chief Executives, stalled initial efforts to pass a get-tough approach that would have made emission cuts mandatory. The Council argued that implementing the measures would cripple the Canadian economy and give US competitors an even greater advantage, since Washington has refused to sign the accord.

New technology will take care of the climate change problem over time, the Council argues in an April 2004 position paper.

Ottawa has been pursuing a voluntary approach, while rolling out a campaign called "The One-Tonne Challenge," which encourages consumers to cut greenhouse gas emissions by one tonne per household. But that approach, which relies on $20 \%$ of Canada's total reductions to come from consumers, versus only $15 \%$ from industry, ignores the reality that 700 oil and gas producers, electricity stations, mines and manufacturers produce $50 \%$ of Canada's emissions.
The voluntary approach has so far failed, as the Globe and Mail revealed in leaked federal documents dated Jan. 5. The document warned that "with current policy and programs, Canada is still going to be significantly off the Kyoto target."

Environment Canada has instead proposed a plan that embraces more regulation and the use of consumer and tax incentives to change behaviour. The plan advocates market-based initiatives such as international carbon trading and investment in projects to credit Canada with reductions when emissions are tallied on a global scale. The plan also relies more heavily on renewable energy.

By contrast, Natural Resources Canada proposes offsetting the emission cuts required of industry with federal investments in energy efficiency and having Canada's forests classified as "carbon sinks" under the international rules, giving Canada credits. - Laura Eggertson, CMAJ

\section{ETHICS}

\section{Media Doctor prognosis for health journalism}

A group of Australian academics and clinicians have put medical reporting of new treatments under the microscope with Media Doctor (www .mediadoctor.org.au).

Funded by the Newcastle Institute of Public Health, Media Doctor reviews a selection of current news items about medical treatments, assesses their quality using a standardized rating scale and presents reviews of good and bad exam\& ples. Researchers use 10 criteria to rate such attributes as the novelty of the treatment, alternatives mentioned, whether there is evidence of disease mongering, whether the benefits and harms were fairly reported and whether conflicts of interest or costs are mentioned. Media Doctor expects these independent and objective critiques will improve the accuracy of medical reporting.

One of the sites' founders, Dr. David Henry, a professor of clinical pharmacology at the University of Newcastle, says improved standards of journalism are definitely needed because of the potential for harm an erroneous article can yield and the powerful vested interests in health technologies.

Generally, news coverage of new medical treatments is regarded as poor and is prone to exaggeration, Media Doctor states.

Plans are already under way to improve the site, including providing more detailed infor- mation on specific health coverage to senior media staff.

Media Doctor now focuses on the Australian media, but André Picard, a Globe and Mail health reporter, thinks Canadians would "absolutely" be interested in a similar service. "I think a Media Doctor, if it is consistent and fair, would be well-read and influential - though perhaps journalists would be reluctant to admit that is the case!"

Researchers in Pakistan, New Zealand and Canada have all expressed interest in replicating the service. Henry says he'd be delighted to see other countries evaluate their health journalism so that international comparisons could be made. - Alan Cassels, Victoria 